\title{
Evaluation of hormonal and metabolic factors related to depression in reproductive age women
}

\author{
Mónica Flores-Ramos, ${ }^{1}$ Martín Armando Burrola-Suárez, ${ }^{2}$ Rodrigo Guiza-Zayas, ${ }^{3}$ J. Miguel Enciso-Araujo, ${ }^{4}$ \\ Dannia Islas-Preciado, 5,6 Erika Estrada Camarena ${ }^{5}$
}

Dirección de Enseñanza, Instituto Nacional de Psiquiatría Ramón de la Fuente Muñiz, Ciudad de México, México.

2 Departamento de Servicio Social, Universidad de Sonora, Campus Hermosillo, México.

3 Departamento de Servicio Social, Universidad Durango Santander, Campus Hermosillo, México.

${ }^{4}$ Departamento de Servicio Social, Universidad de Guadalajara, Guadalajara, Jalisco, México.

5 Laboratorio de Neuropsicofarmacología, Instituto Nacional de Psiquiatría Ramón de la Fuente Muñíz, Ciudad de México, México.

- Centre for Brain Health, University of British Columbia. Vancouver, Canada.

Correspondence:

Mónica Flores-Ramos

Departamento de Enseñanza, Instituto Nacional de Psiquiatría Ramón de la Fuente Muñiz.

Calzada México-Xochimilco 101

Col. San Lorenzo, Huipulco, Tlalpan,

14370, Ciudad de México, México.

Phone: +52 (55) 4160 - 5126

Email: flores_ramos@hotmail.com

Received: 20 November 2019

Accepted: 17 December 2019

Citation:

Flores-Ramos, M., Burrola-Suárez, M. A., Guiza-Zayas, R., Enciso-Araujo, J. M., Islas-Preciado, D., \& Estrada Camarena, E. (2020). Evaluation of hormonal and metabolic factors related to depression in reproductive age women. Salud Mental, 43(1), 35-4 1 .

DOI: $10.17711 /$ SM.0185-3325.2020.006

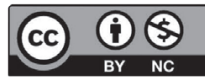

\begin{abstract}
Introduction. Major depressive disorder (MDD) is a prevalent disease affecting women more than men worldwide. Various factors are involved in the genesis of depression, including hormones such as testosterone and certain metabolic factors Objective. To evaluate hormone levels and metabolic variables in women with major depression and healthy controls. Method. A cross-sectional, comparative analytical study was conducted in 40 participants, 23 patients with an MDD diagnosis and 17 controls, all of women in reproductive age between the ages of 18 and 45 . Sociodemographic variables, hormonal profile, and metabolic variables were assessed and the 17-item Hamilton Depression Scale was used to evaluate depressive symptoms. Results. No statistically significant differences were observed between the groups in the hormonal and metabolic variables explored. Nevertheless, it was observed that the lower the testosterone levels and the higher the serum glucose levels, the more intense depressive symptoms were. Discussion and conclusion. Testosterone is associated with a lower depressive symptoms score on the Hamilton Depression scale, suggesting a potential antidepressant effect, whereas high glucose levels are associated with a higher score on this scale. We believe that the measurement of hormonal and metabolic variables in women can contribute to a better understanding of the pathophysiology of depression.
\end{abstract}

Keywords: Major depressive disorder (MDD), testosterone, glucose, hormones.

\section{RESUMEN}

Introducción. El trastorno depresivo mayor (TDM) es una enfermedad prevalente a nivel mundial, que afecta más a mujeres que a hombres. En la génesis de la depresión se consideran diversos factores, entre ellos algunas hormonas como la testosterona y ciertos factores metabólicos Objetivo. Evaluar los niveles de hormonas y variables metabólicas en mujeres con depresión mayor y controles sanas. Método. Se realizó un estudio transversal, comparativo y analítico en 40 participantes, 23 pacientes con diagnóstico de TDM y 17 controles, todas ellas mujeres de 18 a 45 años en periodo reproductivo. Se evaluaron variables sociodemográficas, perfil hormonal y variables metabólicas, y se aplicó la Escala de Depresión de Hamilton de 17 reactivos para evaluar los síntomas depresivos. Resultados. No se observaron diferencias estadísticamente significativas entre los grupos en las variables hormonales y metabólicas exploradas. Sin embargo, se observó que, cuanto menores eran los niveles de testosterona y mayores los de glucosa sérica, los síntomas depresivos eran de mayor intensidad. Discusión y conclusión. La testosterona se asocia con un menor puntaje de síntomas depresivos en la Escala Hamilton, lo que sugiriere un potencial efecto antidepresivo, mientras que los niveles altos de glucosa se asocian con un mayor puntaje en dicha escala. Consideramos que la medición de variables hormonales y metabólicas en la mujer puede contribuir a mejorar el conocimiento de la fisiopatología de la depresión.

Palabras clave: Trastorno depresivo mayor (TDM), testosterona, glucosa, hormonas. 


\section{INTRODUCTION}

Major depressive disorder (MDD) is a prevalent disease worldwide, affecting more women than men, being approximately twice as likely as men to develop it during their lifetime (Kuehner, 2017); it is estimated to affect between $8 \%$ and $16 \%$ of women in reproductive age in the United States (Ko, Farr, Dietz, \& Robbins, 2012). It is a high cost disease in terms of global health, since it limits psychosocial activities (de la Roca-Chiapas et al., 2013), and is the third leading cause of disability worldwide (Institute for Health Metrics and Evaluation, 2018).

Various explanations for the neurobiology of depression have been put forward in recent years, including pathways related to sex hormones and certain metabolic factors (Bromberger \& Epperson, 2018; Studd \& Panay, 2004; Willner, Scheel-Krüger, \& Belzung, 2013). Due to the disparity in prevalence between sexes, it has been propounded that gonadal hormones play a role in its pathophysiology (Studd \& Panay, 2004).

In MDD, hormones and metabolic factors can be understood as part of an interactive matrix, in which all parts play a role. Among the hormones studied, the role of testosterone has been acknowledged in men, although its role in the genesis of female depression is controversial (McHenry, Carrier, Hull, \& Kabbaj, 2014).

The literature has reported contradictory results in this regard (Celec, Ostatníková, \& Hodosy, 2015). However, in a previous study, we found that testosterone has a potentially anxiolytic and anti-depressant effect, increasing GABA+ levels in the posterior cortex of the cingulum (Flores-Ramos et al., 2019). Conversely, several studies have documented the effect of testosterone on modulating insulin resistance. It has even been observed that androgen deprivation therapy increases the risk of suffering from type 2 diabetes mellitus (Arthur et al., 2017; Atlantis et al., 2016; Basaria, Muller, Carducci, Egan, \& Dobs, 2006). These effects could be related to metabolic changes observed in patients with depression such as high levels of serum glucose and glycated hemoglobin ( $\mathrm{HbA} 1 \mathrm{c})$, as well as the relationship between the consumption of high glycemic index diets and a high risk of depression (Salari-Moghaddam, Saneei, Larijani, \& Esmaillzadeh, 2019). However, the interrelationship between testosterone and glucose in women with MDD has yet to be explored. Based on the above, we evaluated hormone levels and metabolic variables in women with major depression and healthy controls.

\section{METHOD}

\section{Study design}

A cross-sectional, analytical, comparative study was conducted between a group of women with MDD and a group of healthy women. The study was conducted in the outpatient clinic of the Instituto Nacional de Psiquiatría Ramón de la Fuente Muñiz.

\section{Participants}

Women aged 18 to 45 who were seeking outpatient services at the Instituto Nacional de Psiquiatría Ramón de la Fuente Muñiz and had been diagnosed with MDD according to the evaluation of the assigned psychiatrist. For the control group, women of the same age were invited by means of posters placed around the premises of the Instituto Nacional de Psiquiatría, through which they were informed about the study, its importance, and participation criteria.

Patients' MDD diagnosis was confirmed at a second evaluation through the International Neuropsychiatric Interview (MINI), which was also applied to the controls to corroborate the absence of psychiatric pathology. Inclusion criteria for the major depression group included being women aged 18 to 45 with a MDD diagnosis according to DSM-IV criteria, confirmed by the MINI questionnaire, with a score of over 13 on the Hamilton Depression Scale (HAMD-17), and being on reproductive age according to the criteria established by the Stages of Reproductive Ageing Workshop (STRAW). STRAW is a staging system of the reproductive age, considered the gold standard for the characterization of the stages involved in menopause. In this study, we included women in stages marked -5 to -3 (regular menstrual cycles) (Harlow et al., 2012). The control group comprised women of reproductive age, stages -5 to -3 according to STRAW, without a diagnosis of MDD or other psychiatric disorders, corroborated by the MINI questionnaire (Heinze, Sheehan, \& Cortés, 2000; Sheehan et al., 1998).

In both groups, women with suicidal intent, who used hormonal, antiepileptic, or psychotropic medication, who had a severe medical illness or psychiatric comorbidity, except for cases of anxiety disorders, patients who had consumed alcohol in the past two weeks or used illegal substances in the past six months and those who had received electroconvulsive therapy or transcranial magnetic stimulation at some time in their lives were excluded.

\section{Evaluations}

\section{Psychiatric interview}

A full psychiatric interview was conducted by the pre-consultation service of the Instituto Nacional de Psiquiatría, in which the MDD diagnosis was determined. 


\section{MINI}

The International Neuropsychiatric Interview (MINI) is a brief, structured diagnostic interview that explores the main psychiatric disorders of Axis I of DSM-IV and the International Classification of Diseases $10^{\text {th }}$ Revision (ICD-10), which was used to confirm an MDD diagnosis (Bobes, 1998). Intended to be applied by psychiatrists and non-psychiatrists once they have received brief training, it was designed and developed by Lecrubier and collaborators at the Salpêtrière in Paris and Sheehan and collaborators at the University of Florida in Tampa in 1992, 1994, and 1998. (Heinze et al., 2000; Sheehan et al., 1998).

\section{Hamilton Depression Scale}

The Hamilton Depression Scale is a 17-item scale applied by the interviewer, designed to quantitatively assess the severity of symptoms and assess changes in the depressed patient. The patient is assessed according to the information obtained in the clinical interview, complemented by information from secondary sources (Ramos-Brieva \& Cordero Villafáfila, 1986). The original version consisted of 21 items subsequently reduced to 17 (Hamilton, 1960), which is the version recommended by the US National Institute of Mental Health. The items have between three to five possible responses, with a score of $0-2$ or $0-4$ respectively. The total score ranges from 0 to 52 . Different cut-off points can be used when classifying depressive symptoms. One of them is without depression, with a score of 0 to 7 , mild depression from 8 to 13 points, moderate depression from 14 to 18 points, and severe depression, with a score greater or equal to 19 (Hamilton, 1960).

\section{Laboratory studies}

Blood samples for laboratory tests were obtained between 7:00 and 9:00 am, after a 12-hour fast. Tests included the quantification of serum glucose, blood count, T3, T4, TSH, uric acid, creatinine, total cholesterol, HDL, LDL, estradiol, progesterone, luteinizing hormone, follicle stimulating hormone, total testosterone, and free testosterone, in accordance with the procedures of safety and quality standards of the Clinical Laboratory of the Instituto Nacional de Psiquiatría.

\section{Procedure}

Patients with MDD were diagnosed by a trained psychiatrist according to the criteria established in the fourth edition of the Diagnostic and Statistical Manual of Mental Disorders (DSM-IV). The MINI inventory was applied to confirm the diagnosis and assess comorbidities. A complete medical history was obtained from patients, which included sociodemographic and clinical information, together with a his- tory of their menstrual cycle in order to select only patients in stages -5 to -3 in STRAW. Severity of depression was assessed using HAMD-17, and only patients with a score equal to or greater than 13 points were included. Patients who met the inclusion criteria were subsequently invited to attend to the Clinical Laboratory of the Instituto Nacional de Psiquiatría to have their serum glucose, blood count, T3, T4, TSH, uric acid, creatinine, total cholesterol, HDL, LDL, estradiol, progesterone, luteinizing hormone, follicle stimulating hormone, total testosterone, and free testosterone measured.

\section{Statistical analysis}

Descriptive statistics were performed with central tendency and dispersion measures as appropriate. Hormonal and metabolic variables were compared between the groups using a two-tailed T test. Pearson's correlation test was subsequently performed between metabolic and hormonal variables and the HAMD-17 score. Finally, a linear regression analysis was carried out, using the progressive method of subtraction of variables, with HAMD-17 scores as the dependent variable and hormonal and metabolic measurements as the independent variables. A statistical analysis was conducted using the IBM SPSS version 20; $p<.05$ was considered statistically significant.

\section{Ethical considerations}

This study was conducted with the prior approval of the ethics and research committees of the Instituto Nacional de Psiquiatría Ramón de la Fuente Muñiz, protocol number DSC-16-261435. All the procedures in the present study were implemented after informed consent had been obtained, and the use of information for research purposes, data protection, confidentiality, and anonymity of the participants had been guaranteed.

\section{RESULTS}

The analysis included 40 female participants, 17 in the control group and 23 with a MDD diagnosis, with an average of 30 years of age (and an age range of 19 to 46 years). A total of $47.5 \%$ of the participants were employees, $30 \%$ students, $20 \%$ homemakers, and $2.5 \%$ unemployed. Sixty-five per cent of participants were single, $32.5 \%$ married or partnered, and $2.5 \%$ divorced (Table 1 ).

A statistically significant negative correlation was found between the HAMD-17 score and free testosterone serum levels $(\mathrm{r}=-.387, p=.012)$. No correlation was found between the HAMD-17 scores and the rest of the variables studied. Regarding metabolic variables, a statistically significant positive correlation was found between HAMD-17 
Table 1

Sociodemographic data of participants

\begin{tabular}{lcccc}
\hline & MDD & Control & & \\
& Mean $(s d)$ or $n(\%)$ & Mean $(s d)$ or $n(\%)$ & & \\
& $n=23$ & $n=17$ & $X^{2}$ & $p$ \\
\hline Age & 31.96 & 28.82 & 17.494 & .681 \\
Occupation & & & 14.766 & .005 \\
Employed & 6 & 12 & & \\
Unemployed & 1 & 1 & & \\
Student & 8 & 4 & & \\
Homemaker & 8 & 0 & & \\
Marital status & & & & \\
Married or partnered & 10 & 3 & & \\
Single & 12 & 14 & & \\
Divorced & 1 & 0 & & \\
Schooling (years of study) & $3(13)$ & $0(0)$ & & \\
Elementary school & $3(13)$ & $1(5.8)$ & & \\
Middle school & $3(13)$ & $0(0)$ & & \\
High school & $11(48)$ & $6(35.4)$ & & \\
Undergraduate degree & $3(13)$ & $10(58.8)$ & \\
Graduate degree & & &
\end{tabular}

Note: $\mathrm{sd}=$ standard deviation

and glucose $(\mathrm{r}=-.409, p=.009)$. No correlation was found between the rest of metabolic variables and the HAMD-17 score (Table 2).

When comparing the metabolic and hormonal variables between the two groups evaluated, a statistically significant difference was found only in HDL levels, which was significantly higher in healthy women than in patients with MDD (Table 3).

Regression analysis was subsequently performed using the HAMD-17 score as a dependent variable and the val- ues of the metabolic and hormonal variables evaluated in the study as independent variables. Free testosterone was found to be a negative predictor for the HAMD-17 score $(\beta=-.357, p=.015)$ and glucose a positive predictor for the HAMD-17 score $(\beta=.352, p=.016)$. No other significant predictor was found in the rest of the models evaluated, among the hormonal and metabolic variables with the HAMD-17 score (Table 4).

Table 2

Correlation of metabolic and hormonal variables with HAMD-17 score

\begin{tabular}{|c|c|c|c|c|c|c|c|}
\hline & & $M D-17$ & $\begin{array}{c}\text { Glucose } \\
\mathrm{mg} / \mathrm{dl}\end{array}$ & $\begin{array}{c}\text { Triglycerides } \\
\mathrm{mg} / \mathrm{dl}\end{array}$ & $\begin{array}{c}\text { Estradiol } \\
\mathrm{pg} / \mathrm{ml}\end{array}$ & $\begin{array}{l}\text { Free } T \\
\mathrm{pg} / \mathrm{ml}\end{array}$ & $\begin{array}{l}A L L O \\
\mathrm{pg} / \mathrm{dl}\end{array}$ \\
\hline \multirow[t]{2}{*}{ HAMD-17 } & $r$ & 1 & $.409^{*}$ & .240 & -.254 & $-.387^{*}$ & -.097 \\
\hline & $p$ & & .009 & .136 & .113 & .014 & .553 \\
\hline \multirow[t]{2}{*}{ Glucose mg/dl } & $r$ & $.409^{*}$ & 1 & .224 & -.138 & -.124 & -.299 \\
\hline & $p$ & .009 & & .165 & .395 & .446 & .061 \\
\hline \multirow[t]{2}{*}{ Triglycerides mg/dl } & $r$ & .240 & .224 & 1 & -.038 & -.018 & $-.349^{*}$ \\
\hline & $p$ & .136 & .165 & & .814 & .913 & .027 \\
\hline \multirow[t]{2}{*}{ Estradiol pg/ml } & $r$ & -.254 & -.138 & -.038 & 1 & .217 & .102 \\
\hline & $p$ & .113 & .395 & .814 & & .178 & .531 \\
\hline \multirow[t]{2}{*}{ Free testosterone $\mathrm{pg} / \mathrm{ml}$} & $r$ & $-.387^{*}$ & -.124 & -.018 & .217 & 1 & -.283 \\
\hline & $p$ & .014 & .446 & .913 & .178 & & .077 \\
\hline \multirow[t]{2}{*}{ ALLO pg/dl } & $r$ & -.097 & -.299 & $-.349^{*}$ & .102 & -.283 & 1 \\
\hline & $p$ & .553 & .061 & .027 & .531 & .077 & \\
\hline
\end{tabular}

Note: ALLO = allopregnanolone. ${ }^{*} p=<.05$ 
Table 3

Differences by group in hormonal and metabolic variables

\begin{tabular}{lccccc}
\hline & MDD & Control & & & \\
& $n=23$ Mean $(s d)$ & $n=17$ Mean $(s d)$ & $t$ & $d f$ & \multicolumn{1}{c}{$p$} \\
\hline Total cholesterol mg/dl & $179.27(38.04)$ & $177.65(32.09)$ & -.142 & 38 & .888 \\
Triglycerides mg/dl & $150.87(82.77)$ & $114.47(66.84)$ & -1.488 & 38 & .145 \\
HDL mg/dl & $50.87(13.19)$ & $58.94(7.93)$ & 2.405 & 36.711 & .021 \\
LDL mg/dl & $100.13(35.85)$ & $96.29(22.85)$ & -.385 & 38 & .703 \\
T3 $\mathrm{\mu g} / \mathrm{DL}$ & $139.75(33.56)$ & $121.56(27.41)$ & -1.827 & 38 & .076 \\
T4 $\mathrm{\mu g} / \mathrm{DL}$ & $8.48(1.77)$ & $8.04(.83)$ & -1.044 & 33.023 & .304 \\
TSH ul/ML & $4.30(3.4)$ & $2.72(1.26)$ & -1.816 & 38 & .077 \\
Estradiol pg/ml & $85.44(54.96)$ & $116.08(115.46)$ & 1.013 & 21.371 & .323 \\
Total testosterone $\mathrm{ng} / \mathrm{ml}$ & $.36(.15)$ & $.36(.11)$ & .000 & 36 & 1.000 \\
Free Testosterone $\mathrm{pg} / \mathrm{ml}$ & $1.35(.50)$ & $2.43(2.09)$ & 1.912 & 14.980 & .075 \\
Allopregnanolone $\mathrm{pg} / \mathrm{ml}$ & $.5(.04)$ & $.51(.05)$ & .647 & 26.796 & .523 \\
\hline
\end{tabular}

Notes: $\mathrm{df}=$ degrees of freedom; $\mathrm{sd}=$ standard deviation.

Table 4

Testosterone and glucose as predictors of HAMD-17

\begin{tabular}{|c|c|c|c|c|c|c|c|}
\hline & \multicolumn{2}{|c|}{$\begin{array}{l}\text { Non-standardized } \\
\text { coefficients }\end{array}$} & \multirow{2}{*}{$\begin{array}{c}\begin{array}{c}\text { Typified } \\
\text { coefficients }\end{array} \\
B \\
\end{array}$} & \multirow[b]{2}{*}{$t$} & \multirow[b]{2}{*}{$p$} & \multicolumn{2}{|c|}{$95 \% \mathrm{Cl}$ for $\mathrm{B}$} \\
\hline & $B$ & Standard error & & & & Lower limit & Upper limit \\
\hline$\overline{\text { Free T }}$ & -2.222 & .872 & -.357 & -2.550 & .015 & -3.988 & -.456 \\
\hline Glucose & .216 & .086 & .352 & 2.514 & .016 & .042 & .390 \\
\hline
\end{tabular}

Note: Free $\mathrm{T}=$ free testosterone.

\section{DISCUSSION AND CONCLUSION}

In the present study, no differences were found in the hormonal and metabolic variables between depressed women and non-depressed women. However, it is striking that the higher the testosterone levels, the lower the severity of depressive symptoms according to the HAMD-17 score. Results are consistent with those observed by other authors such as Giltay, who reports that low testosterone levels are associated with a higher level of depressive symptoms. This author also observes an association with other disorders such as generalized anxiety, social phobia, and agoraphobia (Giltay et al., 2012). Likewise, a recent clinical study found decreased testosterone levels in both men and women with major depression compared to healthy participants (Asadikaram et al., 2019). Although most studies agree that low testosterone levels in men are related to depression (Ford et al., 2016; Kische et al., 2018; Zarrouf, Artz, Griffith, Sirbu, \& Kommor, 2009), findings for women are inconsistent (Kische et al., 2018; Milman, Sammel, Barnhart, Freeman, \& Dokras, 2015) and appear to depend on the woman's reproductive stage (Fiacco, Walther, \& Ehlert, 2019). In women in transition to menopause, it has been observed that high testosterone levels may be related to MDD (Bromberger \& Epperson, 2018); whereas in young women, no differences are observed in testos- terone levels between depressed patients and healthy controls (Matsuzaka et al., 2013) or both high and low levels are reported in young women with depression (Walther, Wasielewska, \& Leiter, 2019; Weber, Lewicka, Deuschle, Colla, \& Heuser, 2000).

The mechanisms that could mediate the effect of testosterone at the level of the central nervous system include an anti-depressant capacity through various processes such as an increase in neuroplasticity (Kheirbek, Klemenhagen, Sahay, \& Hen, 2012; Leal, Tighe, \& Yassa, 2014), activity in the serotoninergic system, and regulation of stress and the immune system (Walther et al., 2019). At the same time, their anxiolytic and antidepressant effect could be explained through the modulation of GABAergic receptors. In young women, a direct relationship between testosterone levels and GABAergic concentrations in the posterior cingulum, measured through spectroscopy (Flores-Ramos et al., 2019), has been observed. Lastly, Carrier and colleagues propose that the antidepressant effect of testosterone includes its ability to become estradiol at the central level and thus reduce depressive symptoms (Carrier et al., 2015).

The effects of testosterone on various human functions have been studied in isolation; however, metabolic and hormonal pathways appear to modulate mood symptoms jointly. In relation to the metabolic effects of testosterone, it has 
been observed that they depend on a person's sex and stage of development. In women, they predispose to obesity and type 2 diabetes, either by increasing adiposity and insulin resistance, increasing food consumption or decreasing energy expenditure (Morford \& Mauvais-Jarvis, 2016; Asadikaram et al., 2019). Chronic androgenic excess appears to alter metabolic pathways in women. Paradoxically, we find that lower testosterone levels are related to an increase in depressive symptoms, whereas high glucose levels occur in women with more intense depressive symptoms. In this study, these variables were the only ones able to predict scores on the depression scale in young women without drug treatment, which suggests that the interaction between testosterone and serum glucose can jointly modulate the intensity of depressive symptoms.

Like de la Roca Chiapas and collaborators, we found that high levels of seric glucose are associated with more severe depressive symptoms (de la Roca-Chiapas et al., 2013). However, the role played by testosterone in this relationship must be studied in depth and evaluated in specific populations.

It is important to mention the limitations of the present study. In other words, the design of the present cross-sectional study does not allow us to establish causes or consequences among the variables. We do not know whether low testosterone or high glucose cause depression in women or whether the condition of being depressed can modify habits that change the levels of the variables studied. At the same time, significant variables that could influence results were not evaluated such as smoking and physical activity. We also consider that polycystic ovarian syndrome should have been assessed, since it is a comorbidity that could affect testosterone levels. Finally, the sample size of our study is small, therefore subsequent studies with larger populations could help elucidate the relationship between testosterone, glucose, and mood.

In reproductive age women, it was observed that at lower levels of testosterone and higher levels of serum glucose, depressive symptoms are more intense according to the Hamilton Depression Scale. Accordingly, we believe that measuring hormonal and metabolic variables in women can contribute to a better understanding of the pathophysiology of depression.

\section{Funding}

The present study was conducted with financing from CONACYT, protocol number DSC-16-261435.

\section{Conflicts of interest}

The authors declare they have no conflicts of interest.

\section{Acknowledgements}

Norma Bernal-Santamaría, María Estela Nieves, Tania Vázquez Pérez.

\section{REFERENCES}

Arthur, R., Rohrmann, S., Moller, H., Selvin, E., Dobs, A. S., Kanarek, N., ... Van Hemelrijck, M. (2017). Pre-diabetes and serum sex steroid hormones among US men. Andrology, 5(1), 49-57. doi: 10.1111/andr.12287

Asadikaram, G., Khaleghi, E., Sayadi, A., Foulady, S., Ghasemi, M. S., Abolhassani, M., ... Nematollahi, M. H. (2019). Assessment of hormonal alterations in major depressive disorder: A clinical study. Psych Journal, 8(4), 423-430. doi: 10.1002/pchj.290

Atlantis, E., Fahey, P., Martin, S., O’Loughlin, P., Taylor, A. W., Adams, R. J., ... Wittert, G. (2016). Predictive value of serum testosterone for type 2 diabetes risk assessment in men. BMC Endocrine Disorders, 16(1), 26. doi: 10.1186/ s12902-016-0109-7

Basaria, S., Muller, D. C., Carducci, M. A., Egan, J., \& Dobs, A. S. (2006). Hyperglycemia and insulin resistance in men with prostate carcinoma who receive androgen-deprivation therapy. Cancer, 106(3), 581-588. doi: 10.1002/ cncr. 21642

Bobes, J. (1998). A Spanish validation study of the mini international neuropsychiatric interview. European Psychiatry, 13(Suppl 4), 198s-199s. doi: 10.1016/S09249338(99)80240-5

Bromberger, J. T., \& Epperson, C. N. (2018). Depression during and after the perimenopause: Impact of hormones, genetics, and environmental determinants of disease. Obstetrics and Gynecology Clinics, 45(4), 663-678. doi: 10.1016/j. ogc.2018.07.007

Carrier, N., Saland, S. K., Duclot, F., He, H., Mercer, R., \& Kabbaj, M. (2015). The anxiolytic and antidepressant-like effects of testosterone and estrogen in gonadectomized male rats. Biological Psychiatry, 78(4), 259-269. doi: 10.1016/j.biopsych.2014.12.024

Celec, P., Ostatníková, D., \& Hodosy, J. (2015). On the effects of testosterone on brain behavioral functions. Frontiers in Neuroscience, 9, 12-12. doi: 10.3389/ fnins.2015.00012

Fiacco, S., Walther, A., \& Ehlert, U. (2019). Steroid secretion in healthy aging. Psychoneuroendocrinology, 105, 64-78. doi: 10.1016/j.psyneuen.2018.09.035

Flores-Ramos, M., Alcauter, S., Lopez-Titla, M., Bernal-Santamaria, N., CalvaCoraza, E., \& Edden, R. A. E. (2019). Testosterone is related to GABA+ levels in the posterior-cingulate in unmedicated depressed women during reproductive life. Journal Affective Disorders, 242(1), 143-149. doi: 10.1016/j. jad.2018.08.033

Ford, A. H., Yeap, B. B., Flicker, L., Hankey, G. J., Chubb, S. A., Handelsman, D. J., ... Almeida, O. P. (2016). Prospective longitudinal study of testosterone and incident depression in older men: The health in men study. Psychoneuroendocrinology, 64, 57-65. doi: 10.1016/j.psyneuen.2015.11.012

Giltay, E. J., Enter, D., Zitman, F. G., Penninx, B. W., van Pelt, J., Spinhoven, P., \& Roelofs, K. (2012). Salivary testosterone: associations with depression, anxiety disorders, and antidepressant use in a large cohort study. Journal Psychosomatic Research, 72(3), 205-213. doi: 10.1016/j.jpsychores.2011.11.014

Hamilton, M. (1960). A rating scale for depression. Journal Neurology, Neurosurgery, and Psychiatry, 23(1), 56-62. doi: 10.1136/jnnp.23.1.56

Harlow, S. D., Gass, M., Hall, J. E., Lobo, R., Maki, P., Rebar, R. W., ... Group, S. C. (2012). Executive summary of the Stages of Reproductive Aging Workshop +10 : addressing the unfinished agenda of staging reproductive aging. The Jornual of Clinical Endocrinology \& Metabolism, 97(4), 1159-1168. doi: 10.1210/jc.2011-3362

Heinze, M., Sheehan, D., \& Cortés, J. (2000). Mini International Neuropsychiatric Interview (MINI): Spanish version (South and Central America) 5.0.0 DSM-IV. México, DF: Instituto Nacional de Psiquiatría.

Institute for Health Metrics and Evaluation. (2018). Findings from the Global Burden of Disease Study 2017. Seattle, WA: IHME.

Kheirbek, M. A., Klemenhagen, K. C., Sahay, A., \& Hen, R. (2012). Neurogenesis and generalization: a new approach to stratify and treat anxiety disorders. Nature Neuroscience, 15(12), 1613-1620. doi: 10.1038/nn.3262

Kische, H., Pieper, L., Venz, J., Klotsche, J., März, W., Koch-Gromus, U., ... Haring, R. (2018). Longitudinal change instead of baseline testosterone predicts depressive symptoms. Psychoneuroendocrinology, 89, 7-12. doi: 10.1016/j. psyneuen.2017.12.013 
Ko, J. Y., Farr, S. L., Dietz, P. M., \& Robbins, C. L. (2012). Depression and treatment among U.S. pregnant and nonpregnant women of reproductive age, 2005-2009. Journal of Women's Health, 21(8), 830-836. doi: 10.1089/jwh.2011.3466

Kuehner, C. (2017). Why is depression more common among women than among men?. Lancet Psychiatry, 4(2), 146-158. doi: 10.1016/S2215-0366(16)30263-2

Leal, S. L., Tighe, S. K., \& Yassa, M. A. (2014). Asymmetric effects of emotion on mnemonic interference. Neurobiology of Learning and Memory, 111, 41-48. doi: 10.1016/j.nlm.2014.02.013

Matsuzaka, H., Maeshima, H., Kida, S., Kurita, H., Shimano, T., Nakano, Y., ... Arai, H. (2013). Gender differences in serum testosterone and cortisol in patients with major depressive disorder compared with controls. The International Journal of Psychiatry in Medicine, 46(2), 203-221. doi: 10.2190/PM.46.2.g

McHenry, J., Carrier, N., Hull, E., \& Kabbaj, M. (2014). Sex differences in anxiety and depression: role of testosterone. Frontiers in Neuroendocrinology, 35(1), 42-57. doi: 10.1016/j.yfrne.2013.09.001

Milman, L. W., Sammel, M. D., Barnhart, K. T., Freeman, E. W., \& Dokras, A. (2015). Higher serum total testosterone levels correlate with increased risk of depressive symptoms in Caucasian women through the entire menopausal transition. Psychoneuroendocrinology, 62, 107-113. doi: 10.1016/j.psyneuen.2015.07.612

Morford, J., \& Mauvais-Jarvis, F. (2016). Sex differences in the effects of androgens acting in the central nervous system on metabolism. Dialogues Clinical Neuroscience, 18(4), 415-424.

Ramos-Brieva, J. A., \& Cordero Villafáfila, A(1986). Validacion de la version castellana de la escala de Hamilton para la depresion. Actas Luso Esp Neurol Psiquiatr, 14(4), 324-334. Retrieved from https://www.ncbi.nlm.nih.gov/pubmed/3776732

de la Roca-Chiapas, J. M., Hernandez-Gonzalez, M., Candelario, M., Villafaña M. de L., Hernandez, E., Solorio, S., ... Jasso, J. (2013). Association between depression and higher glucose levels in middle-aged Mexican patients with diabetes. Revista Investigación Clínica, 65(3), 209-213.

Salari-Moghaddam, A., Saneei, P., Larijani, B., \& Esmaillzadeh, A. (2019). Glycemic index, glycemic load, and depression: a systematic review and meta-analysis. European Journal of Clinical Nutrition, 73(3), 356-365. doi: 10.1038/s41430018-0258-Z

Sheehan, D. V., Lecrubier, Y., Sheehan, K. H., Amorim, P., Janavs, J., Weiller, E., ... Dunbar, G. C. (1998). The Mini-International Neuropsychiatric Interview (M.I.N.I.): the development and validation of a structured diagnostic psychiatric interview for DSM-IV and ICD-10. The Journal of Clinical Psychiatry, 59(Suppl 20), 22-33; quiz 34-57.

Studd, J., \& Panay, N. (2004). Hormones and depression in women. Climacteric, 7(4), 338-346. doi: 10.1080/13697130400012262

Walther, A., Wasielewska, J. M., \& Leiter, O. (2019). The antidepressant effect of testosterone: An effect of neuroplasticity? Neurology, Psychiatry and Brain Research, 32, 104-110. doi: 10.1016/j.npbr.2019.05.004

Weber, B., Lewicka, S., Deuschle, M., Colla, M., \& Heuser, I. (2000). Testosterone, androstenedione and dihydrotestosterone concentrations are elevated in female patients with major depression. Psychoneuroendocrinology, 25(8), 765-771. doi: 10.1016/s0306-4530(00)00023-8

Willner, P., Scheel-Krüger, J., \& Belzung, C. (2013). The neurobiology of depression and antidepressant action. Neuroscience \& Biobehavioral Reviews, 37(10 Pt 1), 2331-2371. doi: 10.1016/j.neubiorev.2012.12.007

Zarrouf, F. A., Artz, S., Griffith, J., Sirbu, C., \& Kommor, M. (2009). Testosterone and depression: Systematic review and meta-analysis. Journal of Psychiatric Practice, 15(4), 289-305. doi: 10.1097/01.pra.0000358315.88931.fc 